\title{
One Size DOES NOT Fit All: Black British-Born Mental Health Nurses and Factors Influencing their 'National' Health Service Career Progression
}

\author{
Deborah Isaac ${ }^{1}$ \\ University of Greenwich, England
}

\begin{abstract}
Evidence suggests that Black and Minority Ethnic nurses in England's National Health Service significantly lag behind their White counterparts in Bands 8a, 8b, 8c, 8d \& 9 and 'Very Senior Managers' positions. Some attribute unequal positions of these nurses to discrimination, racism, exclusion, classism and other forms of disadvantage. Other factors however, are obscured through the accounts of predominantly Black overseas nurses. National Health Service Trusts' workforce data tends to be gathered using the acronyms BME or BAME. Narrow ascriptions of skin colour or ethnicity to signify experiences of nurses as BME or BAME overlook complexed factors influencing their career. The aim of this study is to understand the career progression of Black British-born nurses as current literature fail to meaningfully account for their experiences. To understand the issues influencing the apparent lag, this study utilised a qualitative approach. Data collection was supported by semi-structured interviews. Unlike other studies, participants revealed very little to suggest discrimination as a hindering factor of career progression. Such a finding indicated that socialised 'British cultural capital' constitutes a strong 'helping factor' to override the 'hindering factor' of their 'Black ethnic identity'. This implies that National Health Service Trusts equal opportunities policy drivers should apply more robust ethnic monitoring and reporting systems. Consequently, its grading structures would be best placed to represent and compare intergroup nuances between ethnic minority nurses. It will become inescapable for the UKs National Health Service not to address intersectional factors of ethnic identity, due to historical and persistent exposure of workforce inequities.
\end{abstract}

Keywords: Black, British, career, ethnicity, nurses, and qualitative study

\section{Introduction}

It is questionable why, as a world renowned and diverse 'National' Health Service (NHS), its Black Ethnic and Minority (BME) nurses lag behind their White counterparts to reach 'Very Senior Managers' (VSM) positions and 8a, 8b, 8c,8d and 9 Bands (Kratt, 2018; NHS Confederation, 2019; Pendleton, 2017; West et al., 2017; Workforce Race Equality Standard [WRES], 2019). Upon qualifying, UK nurses register with the Nursing and Midwifery Council (NMC) as a Band 5. The highest grade is Band 9, however BME nurses invariably occupy Bands $5-7$.

${ }^{1}$ Correspondent e-mail: bernadetteisaac@aol.com 
Non-White nurses are frequently described as BME, 'minority ethnic,' 'ethnic minority nurses' (my preferred term) or BAME (Black, Asian and Minority Ethnic) (Okolosie et al., 2018). Commonality of these umbrella terms are fervently used, for instance in the British media reporting over-representation of coronavirus COVID-19 (Ali, 2020) among 'BAME communities'. When referring to important issues as one's career, to merely homogenise the experiences of ethnic minority nurses' as signified by racism and or discrimination, ignores micro and macro intersectional nuances (Atewologun, 2018; Crenshaw, 1991).

African nurses for example, experience more discrimination in the NHS than do other ethnic minority groups (Iganski \& Mason, 2018; Likupe, 2015; Mann Wall, et al., 2015; West et al., 2017). Attempts to differentiate career barriers and advancement, is the description of ethnic groups as unitary, rendering specificities of ethnicity largely unexplored. An important point concerning conflation is summed up by the Policy Exchange.

Each ethnic minority group has its own cultural tradition and history, occupies a certain place on the socio-economic ladder, is on its own distinct trajectory, and sometimes has several internal divisions. Looking at "BME" alone does nothing to tell us who is making progress and who is falling behind. Moreover, improvements in minority representation could be made by improving the lot of those already doing well rather than increasing the representation of those who need it most (Saggar et al., 2016, p. 18).

This explanation depicts continual trends concerning homogeneity of career development within certain groups. It also raises salient questions. Questions I often pondered are, can the narratives of ethnic minority nurses be similar based upon their 'Blackness' or of another ethnic group? Or, does underlying subtleties differentiate group members? Are British-born nurses exposed to comparable treatment their overseas colleagues reported over the past five decades? Or does being British-born in England translate dissimilar dimensions of ethnic inequality when associated with one's career? Inopportunely, due to an absence of viable ethnic breakdown, reporting outcomes are typically generalised. That ethnic minority nurses, irrespective of being British-born or from overseas, are subject to the same career outcomes based upon colour/ethnicity traits. Undertaking research on Black British-born mental health nurses delivered an insightful consideration of their experience. To achieve this, a qualitative approach using semi-structured interviews was deployed to analyse individual narratives and perspectives.

\section{Ethical Procedures}

The study procedure required obtaining ethical approval. This was attained through the University Research Executive Committee (UREC), followed by the Integrated Research Application System (IRAS). A further application was made to the Health Research Authority (HRA). A requirement was to abide by the NHS Confidentiality Code of Practice and Data Protection Act of 2018 (which implements General Data Protection Regulation - GDPR). This code stipulates safe storage and retrieval of participants' data by using pseudonyms.

\section{Conceptual Framework and Philosophical Perspective}


The theoretical and conceptual framework of intersectionality (Crenshaw, 1991) underpin this study. An intersectional perspective clarifies to the complex and multiple disadvantages experienced by certain groups (Atewologun, 2018). Such perspectives seek to explore the effects and impacts of intersectional multidimensional markers, including race, class, race and gender (Hill Collins \& Bilge, 2020; Kressler, 2020; Smith, 2020). An adjunct to this study, the conceptual intersectional framework is reinforced through social constructionism (Andersen, 2019; Burr \& Dick, 2017; Swarts, 2020). This philosophical perspective proposes the world as created and represented through language, framed within culture, time and space.

Burr and Dick (2017) surmise that, "Our knowledge and understanding are therefore not absolute or final, but instead are framed by 'discourses' which often reflect the ideas of powerful groups in society, acting to disadvantage less powerful groups and individuals" (p. 1). Within these contexts, understanding how Black British-born ethnic minority nurses negotiate hierarchical structures in the NHS is key to the study.

\section{Methods}

At the heart of this study is a desire to capture and affirm the 'voice' of participants' insightful and alternative perspectives (Aspers \& Corte, 2019). It is done in pursuit of producing 'thick' detailed accounts of the nurse's concerns, sentiments and 'lived experiences' (Denzin et al., 2017). One-to-one semi-structured interviews (Evans, 2018) appealed as a method to gain rich insight, and extensively considered in social science research. This data collection offers equality of contribution between participants and researcher (Levitt et al., 2018). Deploying such a method was subject to questions participants had to answer (Guyan, 2018). Analysis of the data sought to address the following: What factors do Black British-born mental health nurses perceive as hindering or helping their career progression?

\section{Basic Participant Profile}

Ten nurses participated in the study. Five occupied Band 5, three Band 6, and two Band 7s with no Band 8a, 8b, 8c, 8d or Band 9 nor in VSM positions. The gender composition was unequal with only one male participant. A possible implication is highlighted in the 'limitations' section. The age ranged from 22-51 years old and nursing experience were between 8 months - 31 years. The nurses obtained either a BSc or PGDip Mental Health Nursing qualification and two of them acquired additional MSc qualifications. Two participants have psychology degrees, one participant has an advanced diploma and another obtained a BSc in an unspecified subject.

Referring to ethnicity, four nurses self-identified as Black British, three said they are Black British African. One is Black British Ghanaian. Another as Afro-Caribbean and the other said they are Black Caribbean. In terms of 'Britishness', interpretation of their ethnicity varied and anomalous, therefore can be a challenge concerning identity (Norrie, 2015).

\section{Data Analysis}

Face-to-face recorded interviews lasted between 30mins-100mins. Data was analysed using MAXQDA version 2020, a software designed for qualitative and mixed methods research data. A range of analytical functions used to arrive at themes for analysis were: coding, thematic summaries, comments and memos, text search and a hierarchical category system (Kuckartz \& 
Radiker, 2019, p. 5). The 'hierarchical categories system' supported evaluating the frequency of participants' answers.

Utilising a thematic analysis (TA) approach (Braun \& Clarke, 2006, 2019), the data was segregated, reflected upon and classified to capture nine hindering and helping themes, explored in turn: (1) Mother is or was a nurse (2) English language proficiency (3) British cultural capital (4) Supportive systems: family/manager/team (5) Networking as an art and building networks (6) Unacceptable accent (7) Personal (internalised) conflicts (8) self-perception: lack of confidence (9) Organisational (externalised) forces.

\section{Mother Is or Was a Nurse}

Some literature suggests that first generation Black nurses discouraged their daughters and female family from pursuing a nursing career (Dhaliwal \& McKay, 2008; Iganski \& Mason, 2018). Baxter (1988) argued that Black nurses would become an 'endangered species' resulting in a decline in recruitment. Those in the profession during the late 1980s, recalled experiencing harassment, discrimination, and other disadvantages. This did not appear to resonate with the Black British-born participants whose mothers' influenced their nursing career.

Grace was the only participant to receive a negative view of nursing. Her mother was a Healthcare Assist and regarded nursing as too hierarchical. Here is what Grace said her mother thought about this profession:

...there is a hierarchy in nursing. She doesn't really favour nursing that much, so she tried to steer me in a different direction.

Grace continues,

No, no, my mum didn't want me to do nursing, even my grandparents as well; they wanted me to do something different other than nursing, but it was something I wanted to do.

However, Grace's decision to become a mental health nurse was because of her mother's mental illness added to a desire to help people. Other nurses, such as Valerie come from a long line of family in healthcare and for whom, their positive experiences were conveyed to her. Valerie described family members' influences:

Well, I was probably influenced by my mum. My mum was a nurse, so I've grown up around nursing and certainly in our family there were a few nurses, and quite a few men and women in the caring profession, sort of probably influenced me from quite a young age. I used to go to work with my mum. Yeah. It was sort of back in the late 70s, early 80s. If there was no childcare, she would take me to work, yeah, she would... So, I'd see nursing, you know, at the cold face...

Jeanette's mother's experience as surrounded by healthcare practitioners was similar to Valerie's. Jeanette states, 
She was a nurse, my aunt was a nurse, another aunt a doctor, consultant. So, to me, you have two kind of splits in the family, but, you know, umm, myself and my mum were the mental health nurses and all my aunts were general health nurses.

Jeanette's own reason for choosing nursing also surfaced at an early age and she reflected,

And I think of the 31 years, I've seen a lot, but one of the things I feel kind of blessed that my journey from where I started as a nine-year-old child, meeting my mum doing nursing in a care home, she had two jobs... and I'm from the age nine upwards, I was always doing something with myself to apply for a job although I was under age.

Like the other nurses, Bianca followed in her mother's footsteps and was attracted to nursing albeit in the Adult field, explaining that,

As well, my mother was a nurse; she was a nurse in the physical side of things. But I did always like nursing, but I didn't want to be an Adult Nurse, so when I put the two together, I was like, ok, this is good, so when I looked into it, I said I want to be a Mental Health Nurse, so here I am...She did, she encouraged me because she likes her job, loved her job. And she said it's really, really good, but I didn't want to do Adult Nursing...I can't deal with that (laugh).

\section{English Language Proficiency}

English language proficiency makes for a strong marker of ethnicity (Brodie et al., 2016). Language ability hampers communication, or is an advantage depending on level of proficiency. Ali and Watson (2018) attributed language as a potential barrier whilst acknowledging it as a salient skill for safe health care. For example, Ali and Watson (2018) investigated the impact upon nursepatient relations. Language difficulties between ethnically diverse nurses was reinforced by feelings of isolation. The power of language acts as an exclusionary or inclusionary process for certain groups and a socially constructed tool (Burr \& Dick, 2017). Acquisition of language in this context, suggests fluency in spoken English and a central helping factor for career progression.

Rose for instance, spoke about language barriers pertaining to other ethnic groups but regarded fluency an advantage concerning British-born nurses.

... when they are saying certain things...the language barrier. I tend to understand it more because I've grown up around this...

Rose deemed language a serious barrier. She acknowledged difficulties some patients had trying to understand certain accents, dialects, verbal expression and different phraseology,

...but one person might be saying it in a different way, they might not understand the other person, so they might struggle. So, that's the only thing with the language barrier. 
Language for Maureen was also perceived a barrier due to verbal expression and articulation, she stated,

...but it might be, you know, where they were brought up, the language barrier. Well, maybe they're not able to articulate and talk the same way and it kind of, you know, equates to they don't know what they mean or what they are doing.

Bianca attributed nurse's language with patient contact, indicating,

Umm, personally, I think because it's language barriers for me. And, I'm not being funny, but I think so, it's a big deal, umm, because sometimes like, it's a big deal for communicating with patients...And I think sometimes in Britain, if your written language is not that great, sometimes it can be really difficult to communicate on that level

Prominence of language for Jamal came from interview scenarios. Those for whom English is not their first language were unable to express themselves with confidence verbally. Jamal's example comes from being a panel member on interviews, he said,

...but because of the of the language barrier, they say things in a certain way which maybe...the panel really kind of lose interest from their conversation...sorry, yeah. So, we kind of lose interest like from what they are saying.

Language does not appear to prevent Black British-born mental health nurses from progression in the NHS. In Francesca's illustration, she was interested in how Ms Brown (pseudonym) conducted herself whilst navigating a high-profile event which Francesca herself attended. It was noticeable how Ms Brown's well-spoken English proficiency enabled her to 'fit' comfortably into an otherwise daunting environment (Hammond et al., 2017).

Yeah. So even if it is about colour and stuff, if they do accept you, there still needs to be that blanket similarity that we speak the same language, right; that says, yeah, you know.

Yvonne claimed being British-born was a definite advantage over many nurses born elsewhere, due to,

...someone who is born here...I just took on the language, yeah, I think it's a bit easier and I know it...Yeah, definitely, definitely. If you can write the English and you can speak it, it helps.

Being born in England seemed to incur a more privileged position compared with ethnic minority nurses, Jeanette stated, 
I think what's come up a lot is language. Right, the language barrier, and I have witnessed it myself, I see it right.

Maureen's, verbal expression and articulation was seen as fundamentally related to language.

Sometimes the way they were brought up...language at times. You know, some people do have the experience, but it might be, you know, where they were brought up, the language barrier. Well, maybe they're not able to articulate and talk the same way and it kind of, you know, equates to they don't know what they are doing. Or did they experience when they just might have a language barrier of expressing themselves vocally.

\section{British Cultural Capital}

In what I refer to as 'British cultural capital', culture from a British perspective is considered a career advantage. Explaining British cultural capital concerns acquisition of social resources. Such credentials may include linguistic fluency, modes of behaviour, level of education to enhance social acceptability. Cultural differences or 'embodied capital' (Pollard \& Alexander, 2019) among indigenous nurses and overseas nurses require critical analysis. Largely because the differences showed that values, language, norms and customs, stand out the most culturally for example, African nurses' (Idang, 2015).

Rose highlighted factors regarding acquisition of British cultural capital which enabled her to be better understood by patients,

...being born here...or maybe because of the setting I am in, I understand more of what my patients are going through when it comes to the culture, the music...umm, when they are saying certain things ...the language barrier. I tend to understand it more because I've grown up around this....

Grace directly linked the importance of cultural norms and career progression by commenting,

I grew up here so I am more familiar with the culture so maybe some people might not get like certain cultural norms that are like placed here... in relation to me knowing the culture because I am born here. It kind of gives me an advantage in that sense.

Jamal observed that cultural mores among colleagues can be misinterpreted. He gave this example regarding different groups who attributed those differences to culture.

...they are not assertive enough or they feel like, oh, if they say something...maybe it might also relate to culture, because I remember growing up, you know, my parents were...I should not look at someone 
who is older than me, in their eyes, right, so it's almost like, you're being rude.

For Audrey, culture was a helping factor of career progression for Black British-born nurses, though noted an irony. Being of African descent, she observed ethnic minority nurses (particularly African nurses) brought their cultures to work. She felt this caused some issues because those staff did not appreciate professional commonalities despite cultural differences.

...the culture here, compared to going back home, they still have the culture from where they come from. Whereas here, it depends on your upbringing...but then we do have an advantage in terms of maybe, how you communicate...verbal communications...sometimes nonverbal as well.

In Audrey's view, culture was also generational. African staff felt she should adhere to her cultural heritage by respecting elders, including work places, stating,

Those that I work with who come from back home, they have this culture thing, that they feel like, you have to show respect because they're older than you...although respect works both ways, but when you are a younger person, they feel that you need to talk to them in a certain manner, but they forget that we're all professionals. I think...they really don't break away from that...they bring their culture and their upbringing into work. Whereas, we that are born here, we can put aside like, your home upbringing and work; that's separate.

Audrey's perception is, British-born nurses are able to separate home and culture from work and professionalism. Perhaps it is easier for Black British-born nurses to maintain this separation without needing to integrate assimilate or assimilate.

\section{Supportive Systems: Family/Manager/Team}

Participants considered it important that any intention to pursue promotion or VSM positions required 'supportive family, manager and/or team' on side. Without either (or preferably all) of those helping factors, attaining these positions can incur difficulties or penalties. For example, women with dependents' obligations. Dhaliwal and McKay's (2008) Report showed an almost 'hidden' understanding required to attain these positions. A good relationship is helpful, so too is 'speaking the same language', socialising with managers and supervisors to secure a healthy working life. Enhancing these professional relationships was considered a meaningful influencer to gain promotion (Miller, 2016).

Certain hindering factors was noticeable in Jamal's case. Whilst he was on the lookout for job promotions, he did not divulge future plans to his manager as he had previously. A lack of trust

and subsequent support became an issue when needing another reference. This time his referee came from a source other than his manager.

Because if my manager knew I was going to go for that position, I don't think she would have obviously supported me... and it even took her a 
while to actually do the reference also. So, I have to get like a very senior person who I did not work with. Umm, then there was a Director called...

For other participants, support was not only given, it was offered and encouraged; like in the case of Francesca. Her team was supportive of each other's continuing professional development (CPD).

...I would say it's just the kind of support you get from people around you and stuff. Yeah, but really I have a supportive family which enabled me to do my two degrees. I've always had kids through the two degrees anyway, so it's just to help kind of get through that. And yeah, the team I work with now and the other Band 6s, they're quite supportive.

Audrey's manager acknowledged and nurtured her potential. His encouragement enabled her to aim higher by pursuing a Master's degree, she recalls,

It was my manager that pushed me to do my Masters in mental health nursing, because he said I should aim higher...Yeah, my potential...so he pushed, he saw my potential and kind of pushed me to applying for the Masters programme, and I enjoy working with the mental health service as well so...I had encouragement.

A secondment opportunity arose and Bianca was encouraged by the team to apply. Competition did not appear to be a factor among her team, indicating,

I think I was supported in the fact that my colleagues on the ward showed me the advert and encouraged me to apply again. And then I did apply, umm and then yeah, it was just a case of... well, my manager was supportive at the time as well because it wasn't a permanent job. It was a secondment; it was about six months, and so they didn't give me any grief, they said yeah, just go, it's fine...no one kind of held you back. Obviously, they didn't want me to go, but yeah, it's like a progression thing; everyone was quite supportive. And when I got the job, the team were very supportive, so that was good.

Supportive family enhanced Yvonne's self-confidence. Inner belief equipped her to handle potential set-backs. There was less questioning of her abilities and more likely, she took opportunities.

I felt like, if this is something I want to do, then no one's gonna tell me otherwise and I had enough support from my family as well, trying to do so...My family...they are very supportive of me with what I am doing. 
Despite experiencing different styles in management, Valerie's managers provided positive supportive systems. She modestly attributed it to luck. Valerie's experience however, could have ended up negative, like other colleagues,

I saw that everyone's had different styles, but all the people who supervised me have been wonderful in their own ways. Different, yes, but great for me. I've never had that experience where I was left unsupported or been in an environment where people haven't enabled me or make me feel as if one should be doing what I'm doing. So, but as I say, it's by luck, it's not been by design.

For others, and particularly Valerie, she found ways to combat any challenges, stating,

The messages come from my family and from my boss that you can't use economy as an excuse. You need just to go and navigate your way around. Don't let people say no to you because of your colour when you want to navigate around. If that door's locked, go find the back door. There's a window to open.

Yvonne's experiences were mixed. She recalled periods when support to progress was not forthcoming from ethnic minority colleagues. Yvonne had not anticipated executing her ambitions would be challenging, and commented,

I didn't always have the support from those I was working with...ethnic minorities...Black nurses. So, I have had some difficulties.

Colleagues questioned why Yvonne (as a Black woman too) should conceive of achieving more than she had done. She learnt that those nurses would not support her professional development. To do so would make things easier for her; nurses like Yvonne already have more opportunities. Incidentally, a job reference had been refused. She sensed that, being born in England with further qualifications, is in itself advantageous. Yvonne eventually felt compelled to leave due to lack of support. She reflected,

I think that brought the obstacles between us, which in the end I had to leave because I wasn't getting the support I needed from there. Yeah...Yeah, because when you're dealing with that kind of thing where you're not getting support from...we're a small group of minorities within the Trust, so you think you have that support from ethnic minorities to support each other to reach their goals, to get as high as we can do, yeah. So when you see and experience things like that, it is very disheartening.

\section{Networking As An Art and Building Networks}

Professional networking and building social networks was an anticipated theme given its importance in modern career development. Networking as an art for many participants involves being actively in search of 'relationships'. Mostly, these were relationships built from the NHS 
Trust, albeit not solely. Establishing professional connections was crucial to promote career goals, resonating with Dhaliwal and Sonia McKay's (2008) RCN Report.

Audrey's assessment of networking meant being on side with managers and judged a good starting point for career advancement, she advised,

I would say befriending the managers (laugh). I know that's what some people do as well, yeah. I've heard nurses from other hospitals for example...although the NHS is a big organisation, but it is a small community because everyone knows everybody which I found it hard to believe as a student, but when I got in...people that don't know you, they will know about you. Yeah, people talk. I was pre-warned when I was a student that when you qualify, don't get on anyone's bad foot, because you might not know them, but they will know of you.

Not only was visibility at the right places important, but also one's demeanour and reputation should be intact. Audrey cautioned that Trusts' are tightknit communities where word and gossip gets around. The art of networking was also emphasised by attending relevant seminars and befriending those in authority.

Yes, I will be doing some networking...networking is a good thing...attending seminars...

Valerie valued networking which supported her involvement with interesting projects.

So, if there was something I wanted, I'll be selective, and I'll find the person I need to find, and in most areas, I've got my 'go to' person. So, if I fancy doing something, I'd sound them out and say, what are the opportunities. Never mind what you see online, what's going on? That's more of an informal thing. But I guess that's not always opened to people is it, because if you don't know networks, you may not be aware of opportunities. A lot of things I've done; weird and wonderful projects and opportunities to work in different areas.

Valerie had networking down to an art form. Compared to other participants, she appeared strategic in approach and ability to manoeuvre her career. Nonetheless, there is acknowledgment of limitations to get involved or invited to relevant networking events.

But I guess that's not always opened to people is it, because if you don't know networks, you may not be aware of opportunities.

Bianca highlighted how important she thought the skill of networking to be, in the following scenario.

...there is a colleague and I've known her for four years and in the last year and a half, her networking has been amazing. And she's actually 
now back doing other stuff; she's now a drug rep for another company, doing lots of different talks and stuff. It's networking, and she's done that really, really well...

When asked if she thought there is an art to networking, Bianca's answered,

Umm, watching her, things have been a lot different. She's done that with two different projects and now she's getting more involved doing other stuff to get herself known and to get herself out there. It doesn't pay to sit down and be quiet and then just apply for a job. You've got to actively do stuff. In (this Trust) they have Quality Improvement Projects...it pays, I think, to do stuff to get involved.

I wanted to know if the colleague Bianca was describing shared her ethnicity; she replied,

No, (laugh), no she's White and she's got 20 odd years' experience on me as well, but yeah (laugh). But I guess because I've known her for the four years since I've been here and when I first started, she was trying to do stuff within the team to be more noticed and it kind of it worked, but when it didn't work. And so, then the next thing is you change your tactics and you think, well, if I can't get noticed in the team, I'll get noticed out of the team. And that's how it actually worked.

Although Bianca does not share her the colleagues' ethnicity, it was not an issue in terms of influencing the colleague's effectiveness and opportunities. Instead, Bianca assessed that her colleague utilised opportunities and forged a career path for herself. She stated,

it's networking, she's done that really really well...her networking has been amazing.

Bianca reiterated her emphasis on networking,

...networking is a big thing, it's a big thing. And about, you know, yeah, I get to know people. I think, building your reputation, because I feel like if you're going to be interviewed... they really know you and they know that you're hardworking, it will go in your favour. Rather than you're not just a random person that we don't know yet; rather than reading about you on a piece of paper... So that was what I would say. Networking is important.

\section{Unacceptable Accent}

The extent to which employment is affected by accent, dialect and comprehensibility when linked to ethnicity, is a major factor (Carlson \& McHenry, 2006). Accents delineate geographical location and origin, native tongue and status along social domains. Creese and Kambere's (2003) study of African women immigrants in Canada, aimed to understand what they termed the 'imagined nation'. They sought to ascertain the extent by which 'imagined communities' are 
patrolled through accents. Creese and Kambere (2003) concluded that 'Canadian English' acted as a boundary to allow 'African English' accents 'partial' material rights to housing, jobs and other benefits.

Rose observed the barrier of an accent between nurse and patient. From the patients' perspective, she acknowledged potential difficulties during attempts to understand certain accents, dialects, verbal expression; and how words or sentences are phrased differently.

...but some people would have an accent. So, when they're speaking, the patient would be like, what are you saying?

Francesca provided examples relating to what that might be due to,

...ethnic backgrounds like me, but were born in African countries, maybe with a little bit of an accent...

Francesca mentioned African nurses who she worked with and the effect of accents on their confidence level. Although their jobs were performed competently, confidence was lacking. Francesca gave an example of nurses on her ward being encouraged to apply for a Band 6 post. The overseas nurses were adamant they would not succeed so did not apply. She observed a colleague who concluded,

\section{I don't think we will get it because we have an accent.}

Francesca's colleagues inferred their accents does not equip them to apply for the Band 6 job and she observed,

So, they kind of perceived that because they had an accent and maybe they're going to be looked at a bit differently.

Also, Francesca's colleague presumed only one Black nurse would be offered the job. Her rationale being, this is so the Trust does not exceed ethnic minority staff. Those nurses were convinced Francesca stood a better chance due to her English accent.

But you know, they can only take one of us plus it will probably be you, because you've got an English accent...

Grace referred to perception of others viewed as 'outsiders' who are not born here. She noticed also how those with accents might encounter barriers in seeking promotion,

...they can have their biases towards how they perceive people with accents or that are not born here in this country and I guess that can be a barrier to them maybe getting promoted.

An accent can equate with patients' confidence in a nurse's ability to care for them according to Jeanette. Speaking from the patient's perspective, 
So, if you can't understand their accent, they're thinking, this person don't know anything. Whereas this person may know more than you, me and you, but the accent shouldn't come into it...some patients don't want you, you weren't born here, or I can't understand your accent.

\section{Personal (Internalised) Conflict: Self-Perception}

Self-perception accounted for hindering factors in career development. Namely, belief in how others assess situations through feelings, thoughts and behaviour (Meier et al., 2013). For Meier et al. (2013) this can equate with perceptual, sensory and motor processes, interacting with physical sensations and one's environment.

Audrey asserts the individual may themselves be a barrier. One reason being, perhaps they hold a particular attitude due to personal circumstances or fear of career change,

Yeah and I think there is fear, there's a bit of fear as well. I think when people get into a job, they get a bit complacent, I think the fear of leaving to go into something new, probably scares them.

Francesca's point about perceptions ethnic minorities have about themselves, might influence their ability to progress,

There must be something why many people don't go for the jobs because they think they're not going to get jobs. And that's what you got about it, that perception...I mean, there's an element of your own perception...

Francesca did not hold the view of not putting oneself forward for jobs. She believes perceptions of not being good enough, ultimately affects interview performance - liken to a 'selffulfilling prophecy', she raised,

I personally think that must have affected how they do during interviews, because if you think that, and you think, oh, I'm not good enough, and then that kind of exudes your whole performance...And I do see that a lot, and not even just interviews...just the way people put themselves forward or don't put themselves forward, is due to their perception of what they think other people are thinking of them, because they're from an ethnic background. I know there might be some sort of internal cause.

Valerie was curious about perceptions concerning why people felt they could or could not hold certain positions. She wanted to understand the thought processes behind this mind-set. Also, Valerie was interested in what people thought of her ability to navigate her career relatively unchallenged.

It's probably a bit to do with personalities, but something to do with maybe some people being blocked in certain areas and people's 
perceptions of nurses and them feeling they are not management material. You can't work in this area, but how...It's interesting how that comes to be.

Valerie's confidence level is linked (or embodied) to her self-perception, and shared this perception,

I'll do that, yes, yeah. Yes. I suppose it is a little bit to do with how people perceive you, what you see in yourself and others see in you. Yeah. I was never sort of one to be pigeonholed into anything. I mean, I worked in the area, I worked for a long time, but was always out doing different things and I wouldn't be pigeonholed into one type of nurse or one type of area or cliché...I was always quite happy to be doing different things and to be talking to different people. I wasn't ever really scared about that at all.

Similar to Jamal (who was not fazed by those in power or authority), Valerie also attributed perceptions to elements of what staff thought about power and remarked,

...It's the perceptions of people in power. But also perception, it's your perception. I'm not like that, but I know I struggle to kind of assess what they're thinking about us, for us as a race, as a culture.

\section{Personal (Internalised) Conflict: Lack of Self-Confidence}

Interestingly, this theme featured more strongly than did organisational (externalised) barriers as an inhibiting factor. A lack (or loss) of confidence in ability and skill was associated largely with overseas nurses. This was observed by the Black British-born mental health nurses. The true nature of which had not been ascertained. But it is questionable whether lack of confidence was a consequence of deskilling or whether it was assumed they (mainly African nurses) "are not bothered" about career progress (Pendleton, 2017). Grace stated that,

...maybe...if I am like reflecting on myself, maybe potentially my confidence in terms of applying for those roles, I guess.

Lack of confidence, according to Jamal also affected performance of tasks. Overseas nurses often felt unable to do something or answer a particular question.

This is even when they probably knew the answer, thus effecting their decision-making abilities, pointed out by Jamal,

So, one very common thing, oh, no, talk to the Band 6, let me ask another Band 6. So, even when they know things, they know this is right, but they feel like...let me just ask the Band 6. So, it's not because they don't know what you're doing, but it is almost like...Yeah, their confidence is not there... 
Jamal's persona was confident and he confronted unfair occurrences. This led to him get a reputation and his personality was often at odds with his manager.

I feel like sometimes I take the risk by challenging things which I think is not right. I realised that it wasn't...obviously it wasn't great, but that's just me. If I see something wrong, I would say, because I believe it was wrong, yeah. So we need to say openly and learn from it. So, obviously my manager then and a few senior staff did not like that attitude of me".

Jamal observed British-born nurses were confident with self-expression. They challenged where necessary and were not afraid to express their needs. Perhaps overseas nurses inadvertently reinforced hierarchical systems existing in the NHS. Jamal's example is his ability to communicate with management, Board of Directors and Executives on an equal level. He addressed them on first name terms, often surprising colleagues,

...for example, when I see senior management, I'm the first, I'm almost like, oh, hello, hi. I'm..., nice to meet you. So, what are you doing here today? Sometimes I'll come back to the office and they'll (colleagues) say, oh,...so, do you know that's...yeah, this person and I am like... and so, do you know that's...yeah, ok, it's your colleague, yeah, sometimes I have to remind them of that...it's your colleague and he's not any special than you are, and secondly, he is a human being like yourself".

Jeanette suggested, a lack of confidence might be associated with not being well-educated. However, she admitted this was not necessarily the case, and noted,

One of the things I've noticed that we discussed, sometimes BME staff are not as educated as non-BME. But statistics has shown (and we had a conference about this last week) that there are BME staff who are very educated; a lot of qualifications, but, just not in this role...I think it could be down to confidence and one of the things I think it is, is having the backing of people.

Interestingly, Rose did not wish to 'represent' other ethnic minorities, therefore would not consider progressing to Board level positions. However, she acknowledges it is exceptional to see a Black person in those positions but could not contemplate such a role. Her rationale being,

So, like, being on the Board of Directors, it's hard to spot the Black person. So, it's not something I would want to go into, just because I don't want to be made to feel as if I am representing every ethnic minority; even though they should employ ethnic minorities to understand. 


\section{Organisational (Externalised) Forces}

Participants claimed unfair practices within their NHS Trust organisation hindered career development. Concerns centred on organisational (externalised) forces. An issue which tended to block careers, was transparency in selection and recruitment procedures. Several decades of contributions have bought important attention to this issue, including: Coghill (2017), Dhaliwal and McKay (2008), Henry (2007), Kline (2014), Pendleton (2017), Workforce Race Equality Strategy (WRES) (2019).

Jamal belongs to a group initiated by the Trust. The groups' remit seeks to address anomalies that adversely impact the careers of ethnic minority nurses. The focus being on VSM positions. Jamal observes,

...there has been... has been quite a lot of discussions around ethnic minorities not being... they kind of...they go... the highest is like a Band 7 or ward manager or in high positions, they're quite limited which is quite...very evident in, even in the Trust. When you look at all the executives and you don't see a single ethnic minority on it, photos on the wall... who is a non-director, so which was quite interesting because we constantly have to do these ethnic minority, like training or elearning. However, it does not reflect us as a Trust or organisation, how is this transparent.

Like Jamal, other nurses such as Audrey, felt there was a lack of transparency in job advertisements, and claimed,

Some of them say they think it is a favourism thing. Or when the jobs are put out, there's someone there already, like hired for the job and they don't let you know.

Audrey infers a similar claim, indicating a select few already earmarked for certain jobs,

For example, let's say if there's a Band 6 position, the manager or whoever, it is already known who they are going to give the job to. But they just do it for protocol, but that the position is already filled.

The barriers Audrey perceived was not necessarily personal (internalised) barriers, but general barriers, operating within the organisation. She described NHS Directors as not representing ethnic minority populations, mentioning Black people in particular, questioning,

...I don't understand why Black ethnic minority nurses don't move forward, in terms of levelling up of the higher Bands in the NHS, because normally when you see the pictures for example...NHS directors in the organisations, you don't really see ethnic minorities. I question it, because I know we have intelligent Black people that are working in the NHS, but I don't know why they can't be there too? 
From an organisational level, Audrey also questions the issue of politics that encourages favouritism, and stated,

I don't know if it's favouritism. Or if...or like politics like they say...work politics. I noticed when I was in my other placement, I noticed that the nurse managers were predominately White. And on my last placement, between me and another student nurse, who was Caucasian, she ended up being offered a position there, even though I enquired about it.

This view resonated with Valerie who highlighted the importance of fitting into an organisation.

Or just their face doesn't fit the organisation and can't have that sort of person representing at senior levels.

Valarie stressed there are still preconceived ideas and outdated attitudes where one's face does not fit. Perhaps, it may be difficult for some to envisage a particular type of person holding such high positions and she queried why,

Maybe they're not educated to a high enough standard, but they're just interested doing long hours, but not any kind of career progression. Yeah. Not management material, so good for the shop floor. But they don't really want to be progressing themselves. Yeah, yeah, definitely. Some of the outdated attitudes that people have or just their face doesn't fit the organisation and we can't have that sort of person representing at senior levels for the organisation and those sorts of elements.

Bianca and her colleagues felt certain jobs were only sporadically advertised and displayed for a minimal period. This raises issues of transparency and impedes making an application; largely because of limited time to prepare. Bianca had a lot to say,

Whenever I look, it tends to be managerial jobs. There are other posts that come out, but as me and my colleagues were discussing the other day, some jobs that come up, they're not really fully advertised all the time or for long periods. Because they're kind of like...the people at the top kind of know, and they have their jobs coming out that are available and then you kind of discuss it with people inside, and then they're like, okay, there's a job coming out and it goes out for a day or two and then you know, someone else gets it, yeah.

Unless you knew, kind of got the heads up that it was coming, you know, you wouldn't have known so you wouldn't apply.

A change in mind-set for the interview process is required, according to Jeanette. She asserts however, that introducing initiatives will be ineffective if not complemented by attitudinal change. Making her point clearly, 
I do see there's barriers, I mean, I see barriers for myself, I see barriers for many people. And I think the barriers are, is that, I say, the organisation in itself. And the reason why I said there's barriers, because I think there is no scope to get to that further level.

Jeanette raises a further issue. Equality of this nature for her requires a two-way collaborative approach. Hence, it would appear the Trusts' Chief Executive Officer (CEO) vowed to support an initiative concerning ethnic minority nurses' careers. Jeanette infers,

What I've noticed in this Trust, umm, one of the things, is that, it's not about what you know, it's who you know. And if you're not one of these people who sits in the management...or friends of management, you're not going to aspire to higher. Now, for myself, I've seen these barriers, but I've also turned it around. What can I do to change these barriers that stop me from getting there? So, then, I've now become kind of vocal, focal and have put it to them in their places saying, look, many people would like to be in these positions, but they're not, there's two things. They can either leave or look for positions elsewhere, but if you like your job or the Trust you're in, what can we do, so to stop these barriers?

\section{Discussions}

A critical assessment of the issues was to interpret the findings in a transparent and coherent manner (Kuckartz, \& Radiker, 2019). Honouring that, the findings help to make sense of those earlier queries I pondered about differentiating ethnic group narratives. Namely, that experiences of Black British-born nurses in the NHS required exploration in their own right. This is because previous studies attentive to the impact of ethnicity and nursing career, tend to make similar and overlapping interpretations. That Black nurses 'face does not fit' to occupy senior Bands or 'VSM' positions in the NHS. Furthermore, conclusions drawn tend to be limited in scope due to a lack of an intersectional lens by which to study workplace inequalities.

A crucial revelation also emerged through the themes. Evidence suggests the varying forms of discrimination or racism was a prominent experience of BME nurses in the UK (NHS Confederation, 2020; Pendleton, 2017; West et al., 2015; Woofter, 2019). This corroborates with Ryan's (2007) study on Irish nurse's insider/outsider experiences of conflicting identities. However, discrimination or racism was not a factor which hindered career development to arise from this study.

Instead other striking dynamics were revealed. Such as ways in which Black British-born mental health nurses navigate their career can be determined by 'embodied' (Larsen, 2007) experiences. Thus, British socialisation constituted a prominent feature which helped shape their career to override the 'hindering factor' of 'Black ethnic identity'.

It means the nurses internalised and acquired, not merely a 'cultural capital' (Banks, 2011) for class reproduction, or Moore's (2008) description of Black middle classes 'cultural toolkit', but they internalised what I term as 'British cultural capital'. This is a culmination and embodiment of the nine themes identified. Consequently, there was a deeper appreciation of the nuances involved 
concerning these nurses. Through acquisition of a 'British cultural capital', they appeared able to mitigate discriminatory or racist biases even by omitting to discuss them.

\section{Implications}

Such omission validates the need to debate the reliance upon BME or BAME umbrella terms (Saeed et al., 2019) and its implications. Data which are compelled to categorise nurse's experiences based solely upon skin colour, lacks robustness and often does not consider socioeconomic, political and legal contexts. A continual homogenising of ethnic minority nurse's in the NHS is unhelpful to address their lag in senior Bands or VSM positions. To merely label nonWhite nurses under the acronym BME or BAME, is insufficient to determine which ethnic group require support to attain as far as Board or Director positions. The issue is problematic because BME or BAME are seen as representative of all non-White nurses (Booth, 2014). Consequently, this tendency fails to contemplate factors relatable to one's identity.

The political term 'Black' for example, as an identity marker incurs challenges, innuendos and dilemmas (Rollock et al., 2011) on account of ambiguous usage. Acknowledging this is a significant part of resolving the trend that report lack of career progression of certain groups, by mere acronyms.

These findings ought to be concerning for NHS workforce inequality. It seeks to stimulate NHS Trusts EO policy drivers to apply more stringent ethnic monitoring and reporting systems. This is so that NHS Agenda for Change (AfC) Banding structures represents and compare intergroup nuances between ethnic minority nurses. It will become incumbent upon the NHS to better acknowledge these issues as a fair employer to minimise exposure to the contrary. Concerning that, intersectionality is the conceptual framework (Bakalar, 2018; Crenshaw, 1991) to confront multidimensional issues. As such, the homogenising of certain workforce for ease of inquiry seen with equal opportunities policies agendas.

\section{Study Limitations}

A limitation of this study relates to gender implications. Of the 10 participants, only one male participated. Despite attempts to advertise and attract a more equal gender representation, on this occasion it was not possible, thereby limiting generalisability (Denzin et al., 2017). Nevertheless, contribution from the only male enhanced the findings overall. He (Jamal) provided an in-depth account of many elements relevant to Black British-born mental health nurses and their career.

Another issue was about similarity of my ethnic identity to the population studied. Debates and dilemmas surround whether or not researchers should study those whom ethnic characteristics are shared. Such dilemmas raise reflexive issues of the 'insider/outsider' dichotomy (SerrantGreen, 2002). However, these encounters need not be dichotomous according to Dwyer \& Buckle (2009). For them, it is an acceptable position of the insider and outsider to be 'ever-present' and will not necessarily compromise the research endeavour.

\section{Conclusion and Recommendations}

In claiming originality, findings from this research illustrates a fresh outlook on a welldocumented subject on experiences of non-White nurses in the NHS. This study offers a never before insight into a small sample of Black British-born mental health nurses. Not only does the 
study implicate the academic community, it does so by clarifying researcher positionality. Moreover, to compare and contrast broader equality/inequality literature within multidisciplinary fields.

It was shown that the narrow ascription of skin colour to describe experiences of people as $\mathrm{BME}$ or BAME means important factors were unconsidered. It reinforces a lack of insight into the career differences among groups of nurses. Acknowledging diversity between for instance, overseas nurses and Black British-born was also clarified. This strengthens a necessity for NHS Trusts to explore intersectional nuances to address workforce inequalities. Namely, why ethnic minority nurses lag behind their White counterparts to reach 'VSM' positions. Such an inquiry however, necessitates examination into identity markers of gender, class and ethnicity.

These findings seek to stimulate NHS Trusts equal opportunities policy drivers to apply and audit stringent ethnic monitoring for career progression. This is so NHS AfC Banding structures better compare intergroup career progression because 'one size does not fit all'. It is a concept that will impact upon Britain's healthcare system as they prepare to leave the European Union with a return to nursing recruitment as a global phenomenon.

\section{Funding Details}

This study was not supported by any funding grants or awarding bodies.

\section{Disclosure Statement}

There is no declaration of interest or benefit that has arisen from the direct applications of this research.

\section{Acknowledgments}

I thank the participants for providing such enlightening narratives.

\section{References}

Ali, P., \& Watson. R. (2018). Language barriers and their impact on provision of care to patients with limited English proficiency: Nurses' perspectives. Journal of Clinical Nursing, 27(56), 1-17. https://doi.org/10.1111/jocn.14204

Ali, S. (2020, June 5). 'BAME' is an outdated term, struggling to define the experiences of those who do not identify as White. Varsity. varsity.co.uk/opinion/19351

Andersen, S. (2019). eHealth Systems' User Experiences from Healthcare Workers. Research in Social Sciences and Technology, 4(1), 51-72. https://doi.org/10.46303/ressat.04.01.3

Aspers, P., \& Corte, U. (2019). What is qualitative in qualitative research. Qualitative Sociology, 42, 139-160. https://doi.org/10.1007/s11133-019-9413-7

Atewologun, D. (2018, August). Intersectionality theory and practice. The Oxford Encyclopaedia, Business and Management. Oxford University Press USA. https://doi.org/10.1093/acrefore/9780190224851.013.48

Bakalar, B. (2018). Book Review: Justice on both sides: Transforming education through restorative justice. American Journal of Qualitative Research, 2(2), 145-149. 
Banks, P. A. (2011). Cultural socialisation in Black middle-class families. Cultural Sociology, 6(1), 61-73.

Baxter, C. (1988). The Black nurse: An endangered species: A case for equal opportunities in nursing. Nursing Times Research, 325-338. https://doi.org/10.1177/174498719800300502

Booth, R. (2014). Main parties are still lumping ethnic minorities together, think tank warns. https://www.theguardian.com/world/2014/may/06/political-parties-ethnic-minoritiespolicy-exchange

Braun, V., \& Clarke, V. (2006). Using thematic analysis in psychology. Qualitative Research in Psychology, 3(2), 77101.

Braun, V., \& Clarke, V. (2019). Reflecting on reflexive thematic analysis. Qualitative Research in Sport, Exercise and Health, 11(4), 589-587.

Brodie, K., Abel, G., \& Burt, J. (2016). Language spoken at home and the association between ethnicity and doctor patient communication in primary care: Analysis of survey data for South Asian and White British patients. BMJ Open, 6, e010042. https://doi.org/10.1136/bmjopen-2015-010042

Burr, V., \& Dick, P. (2017). Social constructionism. In B. Gough (Ed.), The Palgrave handbook of critical social psychology (pp. 58-80).

Carlson, H. K., \& McHenry, M. A. (2006). Effect of accent and dialect on employability. Journal of Employment Counselling 43.

Coghill, Y. (2017). Increase in number of senior BME nurses and midwives is great news. Nursing standard (Royal College of Nursing (Great Britain): 1987), 31(37), 30. https://doi.org/10.7748/ns.31.37.30.s27

Creese, G., \& Kambere, E. N. (2003). What Colour Is Your English? Canadian review of Sociology and Anthropology, 40(5), 565-573.

Crenshaw, K. (1991). Mapping the margins: Intersectionality, identity politics, and violence against women of color. Stanford Law Review, 43, 1241-1299. https://doi.org/10.2307/1229039

Denzin, N. K., Lincoln, Y. S., MacLure, M., Otterstad, A. M., Torrance, H., Cannella, G. S., KoroLjungberg, M., \& McTier, T. (2017). Critical qualitative methodologies: Reconceptualizations and Emergent Construction. International Review of Qualitative Research, 10(4), 482-498. https://doi.org/10.1525/irqr.2017.10.4.482

Dhaliwal, S., \& McKay. S. (2008). The work- life experiences of Black nurses in the UK: A report for the Royal College of Nursing. Working Lives Research Institute.

Dwyer, S. C., \& Buckle, J. L. (2009). The space between: On being an insider-outsider in qualitative research. International Journal of Qualitative Methods, 8(1), 1-7.

Evans, C. (2018). Analysing semi-structured interviews using thematic analysis: Exploring voluntary civic participation among adults. SAGE Research Methods Datasets. http://dx.doi.org/10.4135/9781526439284.

Guyan, K. (2018) Analysing Qualitative Data - A Guide for University and College Practitioners. Advance HE.

Hammond, J., Marshall-Lucette, S., Davies, N., Ross, F., \& Harris, R. (2017). Spotlight on equality of employment opportunities: A qualitative study of job seeking experiences of graduating nurses and physiotherapist from black and minority ethnic backgrounds. International Journal of Nursing Studies, 74, 172-180. 
Henry, L. (2007). Institutionalized disadvantage: Older Ghanaian nurses' and midwives' reflections on career progression and stagnation in the NHS. Journal of Clinical Nursing, 16, 2196-2203.

Hill Collins, P., \& Bilge, S., (2020). Intersectionality (Key Concepts) (2nd ed.). Polity Press.

Idang, G. E. (2015). African culture and values. Phronimon, 16(2), 97-111.

Iganski, P., \& Mason, D. (2018). Ethnicity, equality of opportunity and the British National Health Service (2nd ed.). Routledge. https://doi.org/10.4324/9781315190396

Kline, R. (2014). The "snowy white peaks" of the NHS: A survey discrimination in governance and leadership and the potential impact on patient care in London and England. Middlesex University Research Depository.

Kratt, D. (2018). Teachers' perspectives on educator mental health competencies: A qualitative case study. American Journal of Qualitative Research, 2(1), 22-40.

Kressler, B. (2020). Critical Self-Reflection as Disruption: A Black Feminist Self-Study. Journal of Culture and Values in Education, 3(1), 21-38. https://doi.org/10.46303/jcve.03.01.2

Kuckartz, U., \& Radiker, S. (2019). Analysing qualitative data with MAXQDA. Springer International Publishing. https://doi.org/10.1007/978-3-030-15671-8

Larsen, J. A. (2007). Embodiment of discrimination and overseas nurses' career progression. Journal of Clinical Nursing 16, 2187-2195.

Levitt, H. M., Creswell, J. W., Josselson, R., Bamberg, M., Frost. D. M., \& Suaraz-Orozco, C. (2018). Journal Article Reporting Standards for Qualitative Primary, Qualitative MetaAnalytic, and Mixed Methods Research in Psychology: The APA Publications and Communications Board Task Force Report. American Psychologist, 73(1), 26-46. http://dx.doi.org/10.1037/amp0000151

Likupe, G. (2015). Experiences of African nurses and the perception of their managers in the NHS. Journal of Nursing Management, 23(2), 231-241. https://doi.org/10.1111/jonm.12119

Mann Wall, B. (2015) 'I Am a Nurse' Oral Histories of African Nurses. The American Journal of Nursing, 115(8), 22-32. doi: 10.1097/01.NAJ.0000470396.61855.cd

Meier, B., Scholer, A., \& Fincher-Kiefer, R. (2013). Conceptual metaphor theory and person perception. American Psychological Association, 43-64.

Miller, P. (2016). 'White sanction', institutional, group and individual interaction in the promotion and progression of black and minority ethnic academics and teachers in England. Power and Education, 8(3), 205-221.

Moore, K. (2008). Class formations: Competing forms of black middle-class identity. Ethnicities, 8(4), 492-517. https://doi.org/10.1177/1468796808097075

NHS Confederation. (2019) Expo 2019: NHS Confederation BME Leadership Network offers influence, voice and opportunity for BME leaders. https://www.nhsconfed.org/news/2019/09/expo-2019-bme-leadership-network

NHS Confederation. (2020). NHS England and NHS Confederation launch expert research centre on health inequalities. https://www.england.nhs.uk/2020/05/nhs-england-and-nhsconfederation-launch-expert-research-centre-on-health-inequalities/

Norrie., R. (2015) What's in an acronym? A BAME by any other name. INTEGRATION HUB. https://www.integrationhub.net/whats-in-an-acronym-a-bame-by-any-other-name/

Okolosie, L., Harker, J., Green, L. and Dabiri, E. (2018). Is it time to ditch the term 'Black, Asian and minority ethnic' (BAME)? The Guardian. https://www.theguardian.com/commentisfree/2015/may/22/black-asian-minority-ethnicbame-bme-trevor-phillips-racial-minorities. 
Pendleton, J. (2017). The experiences of Black and minority ethnic nurses working in the UK. British Journal of Nursing, 26(1), 37-42.

Pollard, D., \& Alexander, P. (2019). 'An attempt to tip the scales': Music and embodied capital in an English secondary school. British Journal of Sociology of Education. 40(3).

Rasmitadila, R., Aliyyah, R. R., Rachmadtullah, R., Samsudin, A., Syaodih, E., Nurtanto, M., \& Tambunan, A. R. S. (2020). The Perceptions of Primary School Teachers of Online Learning during the COVID-19 Pandemic Period: A Case Study in Indonesia. Journal of Ethnic and Cultural Studies, 7(2), 90-109. Doi: http://dx.doi.org/10.29333/ejecs/388

Rollock, N., Vincent, C., Ball, S., \& Gilborn, D. (2015). Three generations of racism: Black middle-class children and schooling. British Journal of Sociology of Education, 34(5-6), 929-946. https://doi.org/10.1080/01425692.2013.816032

Ryan, L. (2007). Who do you think you are? Irish nurses encountering ethnicity and constructing identity in Britain. Ethnic and Racial Studies. 30(3), 416-438. https://doi.org/10.1080/01419870701217498.

Saeed, A. E., Neil, R., Connell-Hall, V., \& Munro, F. (2019). To BAME or not to BAME: The problem with racial terminology in the civil service. Civil Service World. www.civilserviceworld.com/articles/opinion/bame-or-not-bame-problem-racialterminologycivil-service

Saggar, S., Norrie, R., Bannister, M., \& Goodhart, D. (2016, November 18). Bittersweet success? Glass ceilings for Britain's ethnic minorities at the top of business and the professions.

Policy Exchange. https://policyexchange.org.uk/publication/bittersweet-success-glassceilings-for-britains-ethnic-minorities-at-the-top-of-business-and-the-professions/

Serrant-Green, L. (2002). Black on Black: Methodological issues for black researchers working in minority ethnic communities. Nurse Researcher, 9(4), 30-44.

Smith, A. (2020). Critical Race Theory: Disruption in Teacher Education Pedagogy. Journal of Culture and Values in Education, 3(1), 52-71. https://doi.org/10.46303/jcve.03.01.4

Swarts, G. (2020). Re/coding Global Citizenship: How Information and Communication Technologies have Altered Humanity... and Created New Questions for Global Citizenship Education. Research in Social Sciences and Technology, 5(1), 70-85. https://doi.org/10.46303/ressat.05.01.4

West, E., Nayar, S., Taskila, T., \& Al-Haboubi, M. (2017). A review of the literature on the experiences of Black, minority and internationally recruited nurses and midwives in the UK healthcare system. Royal College of Nursing.

Woofter, S. (2019). Book Review: Building Equity: Policies and Practices to Empower All Learners. American Journal of Qualitative Research, 3(1), 136139. https://doi.org/10.29333/ajqr/5815

Workforce Race Equality Standard (WRES). (2019). A model employer: Increasing Black and minority ethnic representation at senior levels across the NHS. https://www.england.nhs.uk/publication/a-model-employer/

\section{Notes on Contributors}

Deborah Isaac is a retired Senior Lecturer and a qualified Mental Health Nurse. She is nearing the end of her doctorate at the University of Greenwich. Her research interest includes mental health and ethnicity, intersectional concepts, qualitative research, cultural capital, social constructionism and nursing career progression. Her future plan is to collaborate with academics who have similar research and publication interests. 